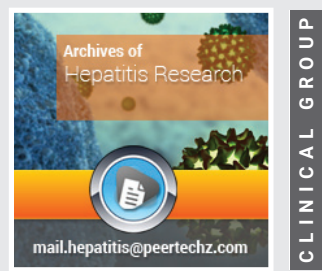

\section{Jing Qiao*}

PhD, Associate Professor, College of Life Sciences, Anhui Medical University, Hefei, Anhui Province, PR China

Received: 03 October, 2019

Accepted: 26 November, 2019

Published: 27 November, 2019

*Corresponding author: Jing Qiao, PhD, Associate Professor, College of Life Sciences, Anhui Medical University, Hefei, Anhui Province, PR China,

Tel: +86-18661655466;

E-mail: 18661655466@163.com

Keywords: Hepatic fibrosis; Liver cirrhosis; Hepatitis; Liver disease

https://www.peertechz.com

Check for updates

\section{Review Article}

\section{Occurrence, diagnosis and management of hepatic fibrosis and cirrhosis: An updated literature review}

\begin{abstract}
Background: Hepatic fibrosis and cirrhosis, characterized with significant morbidity and mortality, have always been worldwide health care problems.
\end{abstract}

Objective: This manuscript is aimed at providing a research progress overview of hepatic fibrosis and cirrhosis.

Method: Online search for articles published in years from 2009 to 2019 with "hepatic fibrosis", "cirrhosis", "therapy", "liver disease" and "hepatitis" as keywords. The adopted database involves PubMed, MIDLINE, Google Scholar, CNKI and EMBASE.

Result: This review summarizes the latest findings about pathogenesis, diagnosis and therapies of hepatic fibrosis and cirrhosis, and describes their application prospect and future research directions, providing references to some extent for fellow academics.

\section{Introduction}

Liver possesses specific regeneration ability, which usually allowes its reconstruction after acute injuries and moderate diseases. In chronic injuries, however, the liver usually unable to repair itself effectively, with fibrosis being the main complication in this process [1]. Hepatic fibrosis may further develop to liver cirrhosis, liver cancer and other serious complications. The pathological basis of hepatic fibrosis is now considered to be abnormal accumulation of extracellular matrix in liver tissue $[2,3]$.

Liver cirrhosis is an end stage of liver fibrosis, which is characterized by fibrotic septa separated regenerative nodules [4,5]. Liver cirrhosis killed 1.2million people worldwide each year, ranking as 10th cause of death in developed countries [6]. Deformation of liver tissue caused by cirrhosis often leads to related serious consequences, such as intravenous bleeding, portal hypertension and ascites $[7,8]$. Clinically, complications of cirrhosis include loss of liver function, esophagus varicose veins, ascites with spontaneous bacterial peritonitis, hepatic encephalopathy, hepato-pulmonary syndrome, hepato-renal syndrome and hepatic encephalopathy and hepatocellular carcinoma $[9,10]$.

At present, major limitations of hepatic fibrosis treatment are accurate \& non-invasive diagnosis and delaying the course of development $[11,12]$. In recent years, many studies focus on hepatic fibrosis and cirrhosis have been conducted, expanding our cognitive territory. The purpose of this review is to integrate the current research progress by searching the existing database of Chinese and Western databases, and to provide suggestions for future research.

\section{Occurrence of hepatic fibrosis and cirrhosis}

Various types of chronic injury may lead to liver fibrosis, such as auto-immune destruction of hepatocytes, metabolic diseases, alcohol abuse, congenital abnormalities, drugs and viral hepatitis $[13,14]$. Since alcoholism is an important deathleading factor among patients with cirrhosis and liver cancers, the association between alcohol and mortality of patients with hepatopathy is obvious [15,16]. In addition, alcohol intake can lead to ascites formation and venous bleeding, according to Peter Jepsen, which further intensify the related complications of liver fibrosis [17]. Possible explanation of association between alcohol intake and chronic liver injury is alcohol potentiation of other hepatotoxins present in the environment at subtoxic levels, according to Hall [18]. Besides, alcohol intake often leads to a rapid increase of portal pressure, which is a common complication of cirrhosis [19]. According to the report, liver fibrosis and cirrhosis is also associated with 
immune dysfunction in various types, justifying liver cirrhosis being descripted as a common immunodeficiency syndrome [20]. Nearly $35 \%$ of patients with liver cirrhosis appear infections with a variety of sources, accounted for $50 \%$ of all fatal results $[21,22]$.

The production of cirrhosis involves three main mechanisms, which are cell death, abnormal matrix deposition (fibrosis) and vascular recombination [23]. Extracellular matrixes accumulation in hepatic fibrosis and cirrhosis is resulted by the activation of fibroblasts and obtaining myo-fibroblastic phenotype [24]. For example, Hepatitis drives activation of precursor cells, such as hepatic stellate cells, generating muscle fibroblasts and leading to liver fibrosis $[25,26]$. It has always been a tough task to develop anti-fibrotic therapies since the associated signal pathways are complex, which make it difficult to identify and modulate the specific targets [27]. Thus, it is essential to figure out the molecular mechanisms underlying the gradual progress of liver fibrosis, which is necessary for developing specific and efficient treatments targeting the cells those are responsible for hepatitis fibrosis and cirrhosis.

Recently, infiltration of immune cells is found to be responsible for the progression of hepatitis fibrosis. Karlmark found that inflammatory Gr1(+) monocytes, which infiltrated into the injured liver via CCR2-dependent bone marrow egress, promoted the progression of hepatitis fibrosis [28]. Therefore, Gr1(+) monocytes may provide an interesting new target for antifibrotic therapies. Besides, Han found that HIF1 mediated PTEN/NF-kBp65 pathway played an important role in the development of nonalcoholic fatty liver disease induced by high fat-diet-and its deterioration into liver fibrosis [29]. Which mains that HIF1 could be targeted for the therapy of fibrosis lesions in liver. In addition, Ma studied a singlenucleotide polymorphism in DNA sequence (rs6834314) and its nearest gene (HSD17B13) to identify their associations with nonalcoholic fatty liver disease. and to characterize the role of HSD17B13 in of of nonalcoholic fatty liver disease She reported that HSD17B13 plays an important functional role in pathogenesis and histological features of nonalcoholic fatty liver disease by way of its enzymatic activity [30]. Thus, HSD17B13 may become a valuable target for gene therapy.

\section{Diagnosis of hepatic fibrosis or cirrhosis}

Liver cirrhosis is characterized normal liver architecture converting into abnormal nodules surrounding by circular fibrosis [31]. This chronic progressive clinical disease always leads to liver cell failure accompanied with portal hypertension, which is benefit to the occurrence of hepatocellular carcinoma [32]. Defining the pathological stage of the hepatic fibrosis is essential for therapy choice and prognosis [33]. At present, liver biopsy is still the gold standard for judgment of fibrosis progression $[34,35]$. Although biopsy is generally accurate in diagnosing of cirrhosis, long-term follow-up in patients with chronic liver disease is always inevitable [36], which brings considerable operating difficulties and great pain to the patients. Therefore, it would be desirable to develop a repeatedly available and non-invasive method for the assessment of hepatic fibrosis [37]. For example imaging techniques and non-invasive serological tests, which have been suggested as trustworthy parameters [38]. Here, the most recent information from papers about helpful non-invasive methods in defining hepatic fibrosis is described.

Diagnostic imaging technology involves numbers of devices and techniques to evaluate hepatic fibrosis and cirrhosis, for instance, ultrasound Doppler, contrast enhanced ultrasound and elastography $[34,39]$. Ultrasound is widely used as the basic imaging check but is inadequate to be an accurate method for estimating disease severity [40]. Besides, many of the diagnostic imaging technologies do not permit investigation or grading of pre-cirrhotic liver disease [41]. Recently, Kirubakaran described a technique for distinguishing the cirrhotic liver from the normal liver by adaptive ultrasound rather than ultrasound images with Hybrid Coupled Dictionary Pairs on Longitudinal Domain [42]. This cirrhosis prediction policy helps to modify the results of traditional ultrasound images with the accuracy of $99.82 \%$, helping to supervise the patient health precisely. However, these techniques have a universal limitation that only very small liver volume can be measured at once, which means potentially uncomprehensive result, and the accuracy of this measurement is very dependent on the professionality of operators [43]. In this case, biomarkers same to be a reliable auxiliary reference to effectively increase diagnostic accuracy.

Serum markers diagnostic techniques are less invasive and theoretically free of complications, providing a cost-effective alternative to liver biopsy testing. Serum markers are divided into direct and indirect markers, which can be used alone or combined to produce compound fractions for diagnosis and evaluation of fibrosis lesions [31]. For instance, The hepatic metabolism ability of patients with cirrhosis is reduced and can be measured by galactose elimination capacity test, which is a strong prediction of mortality [44]. Although blood markers and methods have been proposed for non-invasive assessment of hepatitis fibrosis, international guidelines do not recommend their use due to unsatisfactory accuracy and incomplete verification [45]. Hardy lately uncovered dynamic epigenetic markers of fibrosis measurable in patients' serum, PPAR hypermethylation, that may be useful in non-invasive diagnosis and staging of fibrosis in chronic liver disease patients [46]. Besides, Nonalcoholic Fatty Liver Disease Fibrosis Score (NFS) and Transient Elastography (TE) have been recommended to diagnose advanced fibrosis $[47,48]$. In addition, the union of the M30 biomarker with NFS or TE allows a more dependable identification in patients with progressed nonalcoholic fatty liver disease according to Liebig [49].

Hepatic Venous Pressure Gradient (HVPG) measurement is a useful approach in the administration of portal hypertension in liver cirrhosis [50]. Despite of detecting and classifying the severity of portal hypertension, HVPG measurement also provide reliable prognostic information on the danger of complications, disease advances, and survival [51]. However not all patients are HVPG responders, and there is still no accurate non-invasive biomarker to identify. Fortunately, Reverter recently found in univariate analysis that eighteen metabolites were related to the HVPG response, and integration of two metabolites made a contribution in identifying HVPG responders [52]. 
Valuable Non-invasive scoring system has been established such as NFS that is mentioned above. Augustinho reported that Quick Sequential Organ Failure Score was linked to survival independently, it appears to be an effective way to determine the severity of infection and identify hepatic fibrosis patients with low sensitivity [53]. In multivariate analysis, Zhao found that cirrhosis on transient elastography was relevant to ages, aspartate aminotransferase, and platelet count, but not to alanine aminotransferase [54]. These indexes form the components of the modified Aspartate Aminotransferase To Platelet Ratio Index Sscore, which is favorable in predicting cirrhosis in hepatitis C virus population [54].

With the development of biomedical research, diagnosis methods of hepatic fibrosis and cirrhosis evolve into multilevel and multi-angle accompanied with statistical analysis methods. Diagnostic technique is gradually ameliorating towards more safe, non-invasive, more comfortable and high repeatability.

\section{Management of hepatic fibrosis or cirrhosis}

Hepatic fibrosis is usually invertible, however, liver cirrhosis is generally nonreversible [55]. Therefore, delaying the fibrosis process and avoiding the occurrence of cirrhosis is the main goal of clinical treatment $[56,57]$. In the treatment of hepatic fibrosis, etiology, complications and fibrosis nidus are the main therapeutic objectives [58-60]. The most effective and ideal treatment is to cure the underlying causes of fibrosis lesions before it develops into cirrhosis [61].

Unfortunately, the current treatment of the causes of chronic liver damage can only delay the development of fibrosis. According to the report, sustaining contact with proinflammatory irritation accelerates the pathological process of liver failure [62]. Thus, immune modulation therapies are promising methods for treating hepatic fibrosis, such as blockers of inflammatory signaling pathways [63,64]. Xu found dietary Fisetin intervention could suppress metabolic disorder and hepatic function loss. The mechanism of action involved down-regulating TNF- $\alpha /$ RIPK3 signaling-associated hepatic inflammation and balancing lipid metabolism-related gene expression, and then inhibiting lipid accumulation and steatohepatitis [63]. IL-1Ra, secreted exclusively from tonsilderived mesenchymal stem cells, has been found to defuse the activation of myoblasts to myofibroblast [65]. Conditioned medium from tonsil-derived MSCs display anti-inflammatory and anti-fibrotic effects in the $\mathrm{CCl}_{4}$-injured mouse liver via the endogenous production of IL-1Ra according to Kim [66].

Evidence suggests that Ephrins and its receptors are possible molecular regulations of hepatic fibrosis, promoting fibrotic development in many organs [67]. Therefore, treatment options aiming at Ephrin signaling pathway may be new ways for fibro-therapy [27]. Hepatic fibrosis established in animal model can be degraded by drugs targeting the bioactivities of fibrous hepatic stellate cells, this suggests that the established fibrosis could be reversed and even cured [61]. Verbeke reported that Farnesoid-X receptor agonist obeticholic acid demonstrated preventive and treating effects accompanied with decreased hepatic stellate cell activation on hepatic inflammation and fibrosis in cirrhotic animal model [26]. At present, drugs targeting at the signaling pathway stoking fibrosis are still the most effective and direct strategies for liver fibrosis and cirrhosis treatment. With the insight of fibrosis pathogenesis, new targeted drugs or can fundamentally blocking the occurrence of fibrosis lesions.

Some phytochemicals have shown hepatoprotective effects. Solanum nigrum has been used as therapy for different kinds of ailments associated with gastroenterology and hepatology. Moreover, solanum nigrum was an valuable hepatoprotective reagent on account for its effect of modifying the protein and energy in the liver tissue according to Krithika [68].

As for cell therapy, Duman reported that bone marrowmesenchymal stem cells might inhibit hepatic fibrosis with expanded intrahepatic natural killer cells on common bile duct ligated rat model. Thus, marrow-mesenchymal stem cells therapy seems to be promising candidate for treatment of endstage liver diseases [69].

\section{Summary}

Fibrosis, the main histopathological change of chronic liver injury, develops into cirrhosis once deteriorates, which often leads to serious complications and considerable mortality. Liver biopsy is the most reliable method for evaluating hepatic fibrosis at present. Nevertheless, it still has many drawbacks and cannot give a precise judgment. Early diagnosis of hepatic fibrosis helps to take early intervention timely, avoiding irreversible cirrhosis and other fatal complications, improving prognosis. In addition, it can be treated by anti-inflammation and anti-fibrosis medications. It is urgent to understand pathogenesis and develop more accurate diagnostic methods, as well as exploit new therapies and drugs. Over all, the present and coming information will promote innovation of diagnosis and optimum therapy, thus improving prognosis of hepatic fibrosis, reducing complications and improving cure rate.

\section{References}

1. Xue ZF, Wu XM, Liu M (2013) Hepatic regeneration and the epithelial to mesenchymal transition. 19: 1380-1386. Link: http://bit.ly/34nswSj

2. Shanmugam NP, Karthikeyan P, Dhawan A (2014) Chronic Liver Disease, Cirrhosis and Complications: Part 2: Hepatic Encephalopathy and Other Systemic Effects. Diseases of the Liver in Children 497-516. Link: http://bit.ly/34om02r

3. Su X, Wang Y, Zhou G, Yang X, Yu R, et al. (2014) Probucol attenuates ethanolinduced liver fibrosis in rats by inhibiting oxidative stress, extracellular matrix protein accumulation and cytokine production. Clin Exp Pharmacol Physiol 41 73-80. Link: http://bit.ly/35yac96

4. Kitahata MM, Drozd DR, Crane HM, Van Rompaey SE, Althoff KN, et al. (2015) Ascertainment and verification of end-stage renal disease and end-stage liver disease in the north american AIDS cohort collaboration on research and design. AIDS Res Treat. Link: http://bit.ly/35xueAH

5. Saffioti F, Pinzani M (2015) Pathogenesis and Evolution of Liver Fibrosis: Cirrhosis or Cirrhoses. 3-12. Link: http://bit.ly/35zN3TD

6. Tsochatzis EA, Bosch J, Burroughs AK (2014) Liver cirrhosis. Lancet 383 1749-1761. Link: http://bit.ly/33iHkAk 
7. Eom YW, Shim KY, Baik SK (2015) Mesenchymal stem cell therapy for live fibrosis. Korean J Intern Med 30: 580-589. Link: http://bit.ly/35GQwQF

8. Jang YO, Jun BG, Baik SK, Kim MY, Kwon SO (2015) Inhibition of hepatic stellate cells by bone marrow-derived mesenchymal stem cells in hepatic fibrosis. Clin Mol Hepatol 21: 141-149. Link: http://bit.ly/20kY85b

9. Møller S, Bendtsen F (2015) Complications of cirrhosis. A 50 years flashback 50: 763-780. Link: http://bit.ly/2DiooXN

10. Poordad FF (2015) Presentation and complications associated with cirrhosis of the liver. Curr Med Res Opin 31: 925-937. Link: http://bit.ly/2sj9M8I

11. Noll C, Raaf L, Planque C, Benard L, Secardin L, et al. (2011) Protection and reversal of hepatic fibrosis by red wine polyphenols in hyperhomocysteinemic mice. 22: 856-864. Link: http://bit.ly/2DuawtL

12. Thompson AJ, Patel KJ (2010) Antifibrotic therapies: will we ever get there? Current Gastroenterology Reports 12: 23-29. Link: http://bit.ly/2qLQbgz

13. Harada K (2014) Histological Findings of Autoimmune Hepatitis. 45-65. Link: http://bit.ly/2KWdQII

14. Feyaerts, Broek DV, Heijden DV, Drongelen V, Russel, et al. (2017) Placental transfer of the immunosuppressive drug tacrolimus and its effects on placental function; relevance for renal transplant recipients? ESDPP. Link: http://bit.ly/2rrAfQy

15. Linderoth G, Jepsen P, Schønheyder HC, Johnsen SP, Sørensen HT (2006) Short-term prognosis of community-acquired bacteremia in patients with live cirrhosis or alcoholism: A population-based cohort study. 30: 636-641. Link: http://bit.ly/2seCOAV

16. Hung TH, Tsai CC, Tsai CC, Tseng CW, Hsieh YH (2014) Liver cirrhosis as a real risk factor for necrotising fasciitis: a three-year population-based followup study. Singapore Med J 55: 378-382. Link: http://bit.ly/37GmRc4

17. Jepsen $P, O t t P$, Andersen PK, Vilstrup H (2012) The clinical course of alcoholic cirrhosis: effects of hepatic metabolic capacity, alcohol consumption, and hyponatremia - a historical cohort study. BMC Res Notes 5: 509. Link: http://bit.ly/2Dkr9YK

18. Hall PD, Plummer JL, Ilsley AH, Cousins MJ (2010) Hepatic fibrosis and cirrhosis after chronic administration of alcohol and "low-dose" carbon tetrachloride vapor in the rat. Hepatology 13: 815-819. Link: http://bit.ly/35BOXDw

19. Vorobioff JD, Groszmann RJ (2013) Hepatic venous pressure gradien measurement in pre-primary and primary prophylaxis of variceal hemorrhage. Ann Hepato 12: 22-29. Link: http://bit.ly/2XNCDx6

20. Sipeki N, Antal-Szalmas P, Lakatos PL, Papp M (2014) Immune dysfunction in cirrhosis. World J Gastroenterol 20: 2564-2577. Link: http://bit.ly/2XNCY2Q

21. Hung TH, Tseng CW, Hsieh YH, Tseng KC, Tsai CC, et al. (2013) High mortality of pneumonia in cirrhotic patients with ascites. BMC Gastroenterol 13: 25 Link: http://bit.ly/37HwKGf

22. Mazer LM, Tapper EB, Piatkowski G, Lai MJF, Cárdenas A, et al. (2014) The need for antibiotic stewardship and treatment standardization in the care of cirrhotic patients with spontaneous bacterial peritonitis - a retrospective cohort study examining the effect of ceftriaxone dosing. 3: 459-462. Link: http://bit.ly/2pSnP3T

23. Rosa DP, Bona S, Simonetto D, Zettler C, Marroni CA, et al. (2010) Melatonin protects the liver and erythrocytes against oxidative stress in cirrhotic rats. Arq Gastroenterol 47: 72-78. Link: http://bit.ly/2KWnLat

24. Berardis S, Dwisthi Sattwika P, Najimi M, Sokal EM (2015) Use of mesenchymal stem cells to treat liver fibrosis:Current situation and future prospects. World $J$ Gastroenterol 21: 742-758. Link: http://bit.ly/33rWsLS

25. Lepreux S, Desmoulière A (2015) Human liver myofibroblasts during development and diseases with a focus on portal (myo)fibroblasts. Front Physiol 6: 173. Link: http://bit.ly/20p7Zax
26. Verbeke L, Mannaerts I, Schierwagen R, Govaere O, Klein S, et al. (2016) FXR agonist obeticholic acid reduces hepatic inflammation and fibrosis in a rat model of toxic cirrhosis. Sci Rep 6: 33453. Link: http://bit.ly/20p8u4p

27. Wu B, Rockel JS, Lagares D, Kapoor M (2019) Ephrins and Eph Receptor Signaling in Tissue Repair and Fibrosis. Curr Rheumatol Rep 21: 23. Link: http://bit.ly/2XS9kK2

28. Karlmark KR, Weiskirchen R, Zimmermann HW, Gassler N, Ginhoux F, et al. (2009) Hepatic recruitment of the inflammatory Gr1+ monocyte subse upon liver injury promotes hepatic fibrosis Hepatology 50: 261-274. Link: http://bit.ly/34mMQ6h

29. Han J, He Y, Zhao H, Xu X (2019) Hypoxia inducible factorpromotes liver fibrosis in nonalcoholic fatty liver disease by activating PTEN/p65 signaling pathway. J Cell Biochem 120: 14735-14744. Link: http://bit.ly/2Oknkcg

30. Ma Y, Belyaeva O, Brown P, Fujita K, Valles K, et al. (2019) HSD17B13 is a Hepatic Retinol Dehydrogenase Associated with Histological Features of NonAlcoholic Fatty Liver Disease. Hepatology 69. Link: http://bit.ly/2pQwJ1G

31. Soresi M, Giannitrapani L, Cervello M, Licata A, Montalto G (2014) Non invasive tools for the diagnosis of liver cirrhosis. World J Gastroenterol 20: 18131. Link: http://bit.ly/2sbMDo6

32. Peeters G, Debbaut C, Cornillie P, De Schryver T, Monbaliu D, et al. (2015) A multilevel modeling framework to study hepatic perfusion characteristics in case of liver cirrhosis. 137: 051007. Link: http://bit.ly/2OjLTGe

33. Licata A, Mazzola A, Ingrassia D, Calvaruso V, Cammà C, et al. (2014) Clinical implications of the hyperdynamic syndrome in cirrhosis. Eur J Intern Med 25: 795-802. Link: http://bit.ly/37DrC5X

34. Kim MY, Suk KT, Baik SK, Kim HA, Kim YJ, et al. (2012) Hepatic vein arriva time as assessed by contrast-enhanced ultrasonography is useful for the assessment of portal hypertension in compensated cirrhosis. Hepatology 56 1053-1062. Link: http://bit.ly/34ocx6e

35. Kim MY, Jeong WK, Baik SK (2014) Invasive and non-invasive diagnosis of cirrhosis and portal hypertension. World J Gastroenterol 20: 4300-4315. Link: http://bit.ly/35DxV7I

36. Crossan C, Tsochatzis EA, Longworth L, Gurusamy K, Davidson B, et al. (2015) Cost-effectiveness of non-invasive methods for assessment and monitoring of liver fibrosis and cirrhosis in patients with chronic liver disease: systematic review and economic evaluation. Health Technol Assess 19: 1-409. Link: http://bit.ly/33nmxeW

37. Kim G, Shim KY, Baik SK (2017) Diagnostic Accuracy of Hepatic Vein Arriva Time Performed with Contrast-Enhanced Ultrasonography for Cirrhosis: A Systematic Review and Meta-Analysis. Gut Liver 11: 93-101. Link: http://bit.ly/2DeRWWi

38. Soresi M, Giannitrapani L, Cervello M, Licata A, Montalto G (2014) Non invasive tools for the diagnosis of liver cirrhosis. World J Gastroenterol 20: 1813118150. Link: http://bit.ly/2DeDoGb

39. Jang JY, Kim MY, Jeong SW, Kim TY, Kim SU, et al. (2013) Current consensus and guidelines of contrast enhanced ultrasound for the characterization of focal liver lesions. Clin Mol Hepatol 19: 1-16. Link: http://bit.ly/37HChfZ

40. Cassinotto C, Lapuyade B, Aït-Ali A, Vergniol J, Gaye D, et al. (2013) Liver fibrosis: noninvasive assessment with acoustic radiation force impulse elastography--comparison with FibroScan $\mathrm{M}$ and $\mathrm{XL}$ probes and FibroTest in patients with chronic liver disease. Radiology 269: 283-292. Link: http://bit.ly/35zkcPn

41. Pang JX, Pradhan F, Zimmer S, Niu S, Crotty P, et al. (2016) The feasibility and reliability of transient elastography using Fibroscan®: a practice audit of 2335 examinations. Can J Gastroenterol Hepatol 28: 143-149. Link: http://bit.ly/2QSbmZ6

42. Kirubakaran J, Venkatesan GKDP, Baskar S, Kumaresan M, Annamalai SJMT 
(2019) Prediction of cirrhosis disease from radiologist liver medical image using hybrid coupled dictionary pairs on longitudinal domain approach. Multimedia Tools and Applications 1-19. Link: http://bit.ly/2KV3S3E

43. Bota S, Herkner H, Sporea I, Salzl P, Sirli R, et al. (2013) Meta-analysis: ARFI elastography versus transient elastography for the evaluation of liver fibrosis. Liver Int 33: 1138-1147. Link: http://bit.ly/2QPcAEp

44. Gerlach JC, Brayfield C, Puhl G, Borneman R, Müller C, et al. (2010) Lidocaine/ monoethylglycinexylidide test, galactose elimination test, and sorbitol elimination test for metabolic assessment of liver cell bioreactors. Artif Organs 34: 462-472. Link: http://bit.ly/20kscOA

45. Sebastiani G, Alberti A (2012) How far is noninvasive assessment of live fibrosis from replacing liver biopsy in hepatitis C? J Viral Hepat 19: 18-32. Link: http://bit.ly/33pKu53

46. Hardy T, Zeybel M, Day CP, Dipper C, Masson S, et al. (2017) Plasma DNA methylation: a potential biomarker for stratification of liver fibrosis in nonalcoholic fatty liver disease. Gut 66: 1321-1328. Link: http://bit.ly/20knUGM

47. Aykut UE, Akyuz U, Yesil A, Eren F, Gerin F, et al. (2014) A comparison of FibroMeter? NAFLD Score, NAFLD fibrosis score, and transient elastography as noninvasive diagnostic tools for hepatic fibrosis in patients with biopsyproven non-alcoholic fatty liver disease. Scand J Gastroenterol 1-6. Link: http://bit.ly/2OjK3oP

48. Tapper EB, Sengupta N, Hunink MG, Afdhal NH, Lai M (2015) Cost-Effective Evaluation of Nonalcoholic Fatty Liver Disease With NAFLD Fibrosis Score and Vibration Controlled Transient Elastography. Am J Gastroenterol 110: 12981304. Link: http://bit.ly/2ro24td

49. Liebig S, Stoeckmann N, Geier A, Rau M, Schattenberg JM, et al. (2019) Multicenter Validation Study of a Diagnostic Algorithm to Detect NASH and Fibrosis in NAFLD Patients With Low NAFLD Fibrosis Score or Liver Stiffness. Clin TransI Gastroenterol 10: e00066. Link: http://bit.ly/2sbUr9p

50. Mohkam K, Rode A, Darnis B, Manichon AF, Boussel L, et al. (2018) Hepatic venous pressure gradient after portal vein embolization: An accurate predictor of future liver remnant hypertrophy. Surgery 164: 227-232. Link: http://bit.ly/34qYo8w

51. Delgado MG, Bosch J (2019) HVPG Measurements as a Surrogate of Clinical Events in Cirrhosis: Experience from Clinical Trials. 18: 164-173. Link: http://bit.ly/2KRPysE

52. Reverter E, Lozano JJ, Alonso C, Berzigotti A, Seijo S, et al. (2019) Metabolomics discloses potential biomarkers to predict the acute HVPG response to propranolol in patients with cirrhosis. Liver Int 39: 705-713. Link: http://bit.ly/2pW9FPg

53. Umemura Y, Ogura H, Gando S, Kushimoto S, Saitoh D, et al. (2017) Assessment of mortality by qSOFA in patients with sepsis outside ICU: A post hoc subgroup analysis by the Japanese Association for Acute Medicine Sepsis Registry Study Group. J Infect Chemother 23: 757-762. Link: http://bit.ly/34mxP4n

54. Zhao Y, Thurairajah PH, Kumar R, Tan J, Teo EK, et al. (2019) Novel noninvasive score to predict cirrhosis in the era of hepatitis $\mathrm{C}$ elimination: A population study of ex-substance users in Singapore. Hepatobiliary Pancreat Dis Int 18: 143-148. Link: http://bit.ly/34hSDKh
55. Zhang F, Ni Y, Yuan Y, Yin W, Gao Y (2018) Early urinary candidate biomarker discovery in a rat thioacetamide-induced liver fibrosis model. Sci China Life Sci 61: 1369-1381. Link: http://bit.ly/2XP4IV1

56. Taneja S, Kumar P, Duseja A, Singh V, Dhiman RK, et al. (2016) Honeycomb Cyst of the Liver. 6: 250-251. Link: http://bit.ly/20MQcbX

57. Pinzani M, Rosselli M, Zuckermann M (2011) Liver cirrhosis. Best Pract Res Clin Gastroenterol 25: 281-290. Link: http://bit.ly/35Lmqvp

58. Daneshpour N, Griffin M, Collighan R, Perrie Y (2011) Targeted delivery of a novel group of site-directed transglutaminase inhibitors to the liver using liposomes: a new approach for the potential treatment of liver fibrosis. J Drug Target 19: 624-631. Link: http://bit.ly/2XLdH9C

59. Efe C, Ozaslan E, Kav T, Purnak T, Shorbagi A, et al. (2012) Liver fibrosis may reduce the efficacy of budesonide in the treatment of autoimmune hepatitis and overlap syndrome. Autoimmun Rev 11: 330-334. Link: http://bit.ly/2R3aKA3

60. Gietka JA (2011) Role of simple noninvasive markers of liver fibrosis in qualification to treatment in patients with chronic hepatitis C. 65 : 27-34. Link: http://bit.ly/35zpJ8B

61. Ellis EL, Mann DA (2012) Clinical evidence for the regression of liver fibrosis. $J$ Hepatol 56: 1171-1180. Link: http://bit.ly/2KY4d5I

62. Marques PE, Be F, Menezes BG (2012) Anti-Inflammatory Intervention for Acute Liver Failure: Recent Patents and Future Targets. 2: 147-155. Link: http://bit.ly/20PJwdc

63. Xu M, Ge C, Qin Y, Gu T, Lv J, et al. (2019) Activated TNF-a/RIPK3 signaling is involved in prolonged high fat diet-stimulated hepatic inflammation and lipid accumulation: inhibition by dietary fisetin intervention. Food Funct 10: 1302 1316. Link: http://bit.ly/2XRuM1q

64. Baghy K, lozzo RV, Kovalszky I (2012) Decorin-TGF $\beta$ axis in hepatic fibrosis and cirrhosis. J Histochem Cytochem 60: 262-268. Link: http://bit.ly/2rxWqEB

65. Cho KA, Park M, Kim YH, Woo SY, Ryu KH (2017) Conditioned media from human palatine tonsil mesenchymal stem cells regulates the interaction between myotubes and fibroblasts by IL-1Ra activity. J Cell Mol Med 21: 130 141. Link: http://bit.ly/37lxKtW

66. Kim YH, Cho KA, Park M, Kim HS, Park JW, et al. (2019) Conditioned Medium from Tonsil-Derived Mesenchymal Stem Cells Relieves CCI 4 -Induced Liver Fibrosis in Mice. Tissue Engineering and Regenerative Medicine 16: 51-58. Link: http://bit.ly/20mEN30

67. Barquilla A, Pasquale EB (2015) Eph Receptors and Ephrins: Therapeutic Opportunities. Annu Rev Pharmacol Toxicol 55: 465-487. Link: http://bit.ly/2KX2WLY

68. Krithika R, Verma RJ (2019) Solanum nigrum confers protection against CCl4induced experimental hepatotoxicity by increasing hepatic protein synthesis and regulation of energy metabolism. Clinical Phytoscience 5: 1. Link: http://bit.ly/20TLN7s

69. Duman DG, Zibandeh N, Ugurlu MU, Celikel C, Akkoc T, et al. (2019) Mesenchymal stem cells suppress hepatic fibrosis accompanied by expanded intrahepatic natural killer cells in rat fibrosis model. Mol Biol Rep 46: $2997-$ 3008. Link: http://bit.ly/20oFxWg

Copyright: (c) 2019 Qiao J. This is an open-access article distributed under the terms of the Creative Commons Attribution License, which permits unrestricted use distribution, and reproduction in any medium, provided the original author and source are credited. 